\title{
Centralized to hybrid nurse station: Communication and teamwork among nursing staff
}

\author{
Yuan Zhang ${ }^{* 1}$, Laurie Soroken ${ }^{1}$, Margaret Laccetti ${ }^{1}$, Elizabeth Ronan de Castillero ${ }^{2}$, Afua Konadu ${ }^{1}$ \\ ${ }^{1}$ School of Nursing, University of Massachusetts Lowell, Lowell, United States \\ ${ }^{2}$ Lowell General Hospital, Lowell, United States
}

Received: July 20, 2015

DOI: $10.5430 /$ jnep.v5n12p34
Accepted: August 23, $2015 \quad$ Online Published: September 14, 2015

URL: http://dx.doi.org/10.5430/jnep.v5n12p34

\begin{abstract}
The initiative to redesign nurses' stations is driven by the goals to improve work processes and ensure a safe environment. Both centralized and decentralized stations have posed challenges in meeting the needs of patients and nurses. A hybrid design model connecting the decentralized stations with centralized meeting spaces may address the needs of patients; however, since nurses continue to work in their independent spaces, communication and teamwork among nurses may be impeded. Until recently little attention has been paid to nurses' lived experience at the hybrid station. This qualitative phenomenological study examined nurses' experiences with communication and teamwork at the hybrid station and their reports of the advantages and disadvantages of the hybrid station. Twenty interviews were completed with nursing staff members who were undergoing a transition, over the course of two years, from the centralized design to the hybrid station design. Although nursing staff reported experiencing the challenge of isolation, they consistently identified the following advantages: patient-centered interactions at the hybrid station, and learning to work as a team. Overall, participants reported that the advantages of the hybrid station outweighed the disadvantages. Targeted interventions are needed to reduce the nurses' feelings of isolation and to support teamwork.
\end{abstract}

Key Words: Nurse station transition, Communication, Teamwork, Hospital nurse

\section{INTRODUCTION}

Nurses' stations serve as the workspaces for nurses, doctors, and other members of the healthcare team when they are not working directly with patients. The electronic patient record, coupled with the need to enhance the quality and efficiency of patient care, has resulted in changing from centralized to decentralized or hybrid work stations. Hybrid stations offer workspaces for health care team members to chart inside/outside of patient rooms with a central area to meet when needed ${ }^{[1]}$ which fits patient-centered care models. ${ }^{[2]}$ The Institute of Medicine emphasized the importance of better designed work environments for improved patient care and safety. ${ }^{[3]}$ In response, healthcare institutions are implementing work station designs to improve work processes and promote a safe environment.

Traditional centralized nurses' stations provide spaces for nurses and multidisciplinary team members to meet, communicate, and collaborate. ${ }^{[4]}$ For example, newly orientated nurses may take advantage of the central station to exchange information and solicit advice from experienced nurses prior to initiating a procedure that they are uncomfortable performing. However, the centralized station leads to more frequent use of telephones, computers, and paper administration tasks ${ }^{[1]}$ and less patient care time. ${ }^{[5]}$ Decentralized

*Correspondence: Yuan Zhang; Email: Yuan_Zhang@uml.edu; Address: School of Nursing, 113 Wilder Street, University of Massachusetts Lowell, Lowell, MA 01854, United States. 
nurses' stations are small workspaces located inside or outside of patient rooms. The shorter distance between the station and patient rooms reduces the amount of walking for nurses and thus reduces physical strain. ${ }^{[6]}$ The shorter distance also increases time spent on patient care, ${ }^{[5,7]}$ which has the potential for improvement of therapeutic relationships with patients, and may be associated with increased patient satisfaction. ${ }^{[8]}$ Previous studies also reported reduced noise levels with the decentralized station design. ${ }^{\text {[7 }}$ However, many nurses reported feeling isolated and losing the sense of team connection at the decentralized station. ${ }^{[9]}$ Zborowsky and colleagues reported significantly less consultation with medical staff and social interaction at the decentralized station. ${ }^{[1]}$ The authors concluded that a hybrid design model connecting the decentralized stations with centralized spaces may address both patients' and nurses' needs. ${ }^{[1]}$ Although the hybrid design model has been explored in a few studies, ${ }^{[10-12]}$ these studies quantitatively examined the effect of the hybrid station on patient outcomes and nurse satisfaction. Since nurses continue to work in their independent spaces at the hybrid station, communication and teamwork among nurses may be impeded. Until recently, little attention has been paid to nurses' lived experience, especially their perspectives of communication and teamwork at the hybrid station.

Nurses' work environments and work behaviors are fundamental components that affect health care delivery. A safe and efficient work environment is critical to patient outcomes and patient/family satisfaction. Previous studies encourage the evidence-based design, which suggests that the hospital design needs to be guided by rigorous research linking hospital environment to healthcare outcomes. ${ }^{[13]}$ The evidencebased design indicates that well-designed physical settings are beneficial for both patients and nurses. ${ }^{[13]}$ Nurses rely on each other for support and sense of team cohesion. Communication and teamwork among nurses are not only associated with the safety culture ${ }^{[14]}$ and quality of patient care, ${ }^{[15]}$ but are also associated with staff job satisfaction ${ }^{[16]}$ and, possibly, retention.

The objectives of this study were to (1) explore nurses' experiences with communication and teamwork at the hybrid station; and (2) examine nurses' perceptions of advantages and disadvantages of the hybrid station. This study was conducted through in-depth interviews with nursing staff at a mid-sized tertiary hospital in Massachusetts.

\section{MeTHODS}

\subsection{Study design}

Due to the exploratory nature of the study and the limited existing knowledge, a qualitative approach using phenomenol-

Published by Sciedu Press ogy ${ }^{[17]}$ was chosen to explore nursing staff's experience and perspectives. Qualitative research is useful for investigating complex and poorly understood organizational and human phenomena. ${ }^{[18]}$ Phenomenology attempts to describe and understand the essence of the phenomenon from the viewpoint of those experiencing, therefore, is useful for investigating nursing staff's lived experience at the hybrid station. In-depth semi-structured key informant interviews were conducted with nursing staff who experienced a transition from centralized to hybrid station over the course of two years.

\subsection{Participants and data collection}

This study was conducted at one 30-bed medical-surgical unit and one 30-bed intermediate care unit in an independent, not-for-profit community hospital in Massachusetts. Both units transitioned from a centralized station to a hybrid station (see Figure 1) in November 2012. The hybrid station included a pod design, introducing multiple pod stations with computers and supply closets situated between every two patient rooms. The physical structure of the two units is rectangular with patient rooms on the outside, pod stations outside of patient rooms, and medication rooms and storage spaces in the center. North and south ends of the units each have central workstations where secretaries, resource nurses, physicians and other support staff carry out patient related responsibilities.

A convenience sampling method was used to recruit participants who underwent the station transition. Twenty nursing staff participated in the key informant interviews between February and March 2014.

Each interview was scheduled for one-hour either before or after the work shift at a private conference room on the unit. Two experienced researchers conducted the interviews. Purpose and procedure were explained and participants were asked to sign the informed consent form. All interviews were digitally-recorded and professionally transcribed. Participants completed a short demographic survey at the end of each interview, including information on their job title, education, work schedules, and years of nursing practice. Each participant received a $\$ 30$ cash honorarium for completing the interview and the demographic survey. The study was approved by the Institutional Review Boards at the Lowell General Hospital and the University of Massachusetts Lowell (No. 2013-013).

\subsection{Data analysis}

The two interviewers reviewed the transcripts to sort the data into categories. A start list of themes was created based on the interview guide and review of the transcripts. In order to reduce the subjective interpretation, data was analyzed by the 
two interviewers and two other study investigators through electronically coding the transcripts in Microsoft Word 2010. The following steps were used to analyze the data, including carefully read all transcripts to achieve a deep understanding of the phenomenon; reread the transcripts to phrase descriptions directly related to the start list of themes; find significantly distinctive statements; encode recurrent themes; formulate descriptions into clusters of sub-themes; and identify emergent themes and sub-themes until saturation was achieved. ${ }^{[19,20]}$ Data saturation indicated that no new themes or sub-themes were identified from the transcripts. The code structure and quotes were discussed by the research team. No glaring discrepancies were found. Small discrepancies, such as code definitions, were resolved through interpretive discussions and consensus building. Rigor was maintained through member checking. The research team mailed the transcript analysis results to participants for interpretation and validation, ${ }^{[21]}$ because it is important that the interpretation of the data is based on the participants' perspectives. No participants expressed any disagreement with the list of themes and sub-themes.

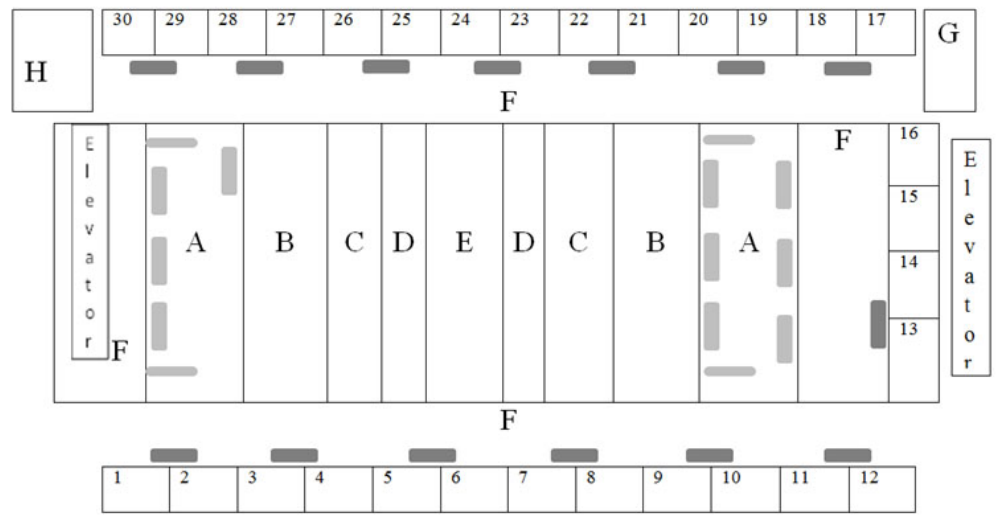

Figure 1. The hybrid nurse station design

No. 1 -30 = patient room; dark grey space = pod nurse station; $A=$ central nurse station; $B=$ medication room; $C=$ clean utility room; $D=$ biological hazard room; $E=$ nutrition room; $F=$ hall way; $G=$ family visiting room; $H=$ break room/conference room

\section{Results}

\subsection{Sample description}

Twenty interviews were completed with nursing staff, including 14 registered nurses (RNs), 1 licensed practical nurse (LPN), and 5 nursing assistants (NAs). The study included participants with a Bachelor's Degree $(n=9)$, an Associate Degree $(n=5)$, or high school education $(n=6)$; working full-time $(n=15)$ or part-time $(n=5)$; working an eight-hour day shift $(n=10)$, eight-hour evening shift $(n=5)$, or twelvehour day shift $(n=5)$; and having more than 10-year nursing practice $(n=9), 6-10$ year nursing practice $(n=5)$, or $1-5$ year nursing practice experience $(n=6)$.

\subsection{Findings}

There were no important differences across the study themes among RNs, LPN, and NAs, therefore, interview data were combined and grouped into four primary themes: communication, teamwork, pros and cons of the hybrid station, and transition to a hybrid station.

\subsubsection{Communication}

Communication, as defined by the Joint Commission $(2010),{ }^{[22]}$ is "a two-way process (expressive and receptive) in which messages are negotiated until the information is correctly understood by both parties" (p.1). In this study, communication was defined as either in-person or distant interaction with other nursing staff during the work shift. Communication at the hybrid station was discussed from both positive and negative perspectives. Although participants stated that interaction with coworkers was not "sacrificed" with advanced technology, they did report feeling isolated at the hybrid station.

\section{Advanced technology enhances distant interactions}

At the hybrid station, nurses were provided with wireless phones to locate and contact with other members of the healthcare team. Participants pointed out that the wireless phones provide a convenient way to communicate. Wireless phones are especially helpful when nurses are alone in a patient's room and need assistance, where they can call for help immediately through wireless phones. Most participants agreed that the wireless phones "enhanced" communication and "it's faster and more effective." The wireless communication decreases physical effort and time to seek for information. Participants described that communication is much more efficient by phone than by face-to-face inter- 
action. Wireless phones are more efficient as well when recruiting help for tasks that require teamwork.

\section{Proximity to patients fosters patient-centered interac- tions}

Participants mentioned that there were more communications focusing on patient care at the hybrid station. The workspaces outside of patient rooms "have less distractions" and are more conducive to giving hand-off reports, for example, "you need to talk to somebody about a drip... you can still point to the room and show them." Although participants agreed that there was less nurse to nurse interaction about personal matters, they thought that the quality of communication was improved by focusing more on patient care. For example, one nurse said, "I think the quality of communication in decentralized is better. Because it's more patient focused. The centralized nurse station... granted a lot more communication, but it's not always about the patient."

\section{Isolation}

Isolation was defined as lack of physical, social, or professional interaction with other nursing staff during the work shift. Most participants identified "isolation" as the biggest challenge of the hybrid station. The structure of the pods makes it difficult to socialize with coworkers; therefore, nursing staff do not see each other until the end of the shift. Isolation was discussed from physical isolation, social isolation, and professional isolation.

1) Physical isolation Physical isolation was defined as lack of physical contact with other nursing staff during the work shift. At the hybrid station, nurses are expected to stay at their pods throughout the shift. They expressed concern that, "you can't even see the pod, no because when people are sitting in their pods, you can't even see if they're there. They kind of disappeared. You look down the hall and there's nobody." One nursing assistant described, "Sometimes I can go a whole shift without seeing another aide."

2) Social isolation Social isolation was defined as lack of social interaction about personal matters with other nursing staff during the work shift. Nursing staff rely on each other for social support and a sense of cohesion, however, the hybrid station makes nurses feel socially isolated, "It's the social aspect... especially for somebody like me - I like to talk. Some people are here for 12 hours, some are here for 16 hours. You do want to talk to somebody else that's not your patient. That's why centralized nursing was always great, you got to vent to your coworkers."

3) Professional isolation Professional isolation was defined as lack of professional interaction about patient care with other nursing staff during the work shift. Since nursing staff are expected to stay in their pods, they do not have the chance to assess work flow across the unit. Participants reported that they were not answering each other's lights "as frequent as" when they were at the centralized station; because they did not know "whose call light is on" unless they "take a peek out." Some participants reported lack of professional interaction, because "It's much harder to find people" and they "don't feel like (they) know what's going on as much" on the floor without frequent interaction with other staff members.

\subsubsection{Teamwork}

Teamwork was defined as requesting or providing help to complete a task with other nursing staff during the work shift. Some participants reported that teamwork was "sacrificed" at the hybrid station due to less face to face interaction. Nurses expressed they had "less of a team feeling" and "feeling more like you're on your own." However, most nurses developed strategies or were in the process of developing strategies to promote teamwork at the hybrid station.

\section{Creating a teamwork environment}

Although the transition period was difficult, nurses expressed that they were trying to create a teamwork environment where nurses felt comfortable to request help or offer help to complete a task with their coworkers. Nurses learned by themselves or from their coworkers that they have to "search out", "seek out", or "approach" coworkers for help. Participants supported the importance of "making (themselves) available" and "offering help" in order to receive help from coworkers. Nurses expressed, "Being approachable, positive, and willing to help makes a difference"; "I try to make myself available. I try to help whenever I can. Offer help when you have time", then "if you ask someone, they'll be more than happy to help you."

At first nurses found it difficult to create a teamwork environment at the hybrid station. "when it first opened, it was a little difficult, because you didn't really realize... people are now being more (helpful)... They want to make sure that their coworkers are doing ok." Participants also discussed spaces for teamwork other than the nurses' station, for example, "I find that the med room is a common place to go and ask questions."

A "pod team" was built at the hybrid station, which was comprised of two nurses and one nursing assistant working as "team buddies". Most nurses like the "pod team", "it's in a way better because you know who to call, and you know that they're relying on you." "Team buddies" helped each other with patients if, for example, one left the floor for a lunch break. "Morning huddles" were initiated one year after the 
transition as the formal shift reports between the charge nurse and the "pod team". Nurses and nursing assistant used the morning huddles to connect with each other and discuss patients' progress. Nurses commented, "that (morning huddle) is pretty effective."

\subsubsection{Pros and cons of the hybrid station}

Since these nursing staff experienced the transition from the centralized station to the hybrid station in the past two years, they expressed some advantages and disadvantages of the hybrid station. Pros and cons of the hybrid station were defined as advantages and disadvantages of the hybrid station over the centralized station for both patients and nurses.

\section{Advantages for patients}

Less nurse socialization reduces noise level Participants identified noise as a result of increased socialization at the centralized station. The hybrid station was a big satisfier for patients as it is "quieter". Nurses expressed, "It's 100\% less noise now."

Proximity to patients increases patient safety Nurses are required to work at the pod station outside of the patients' rooms, which increases the visibility and enables nurses to "respond [the alarm] more readily." The proximity of nurses to patients' rooms contributed to a decrease in patient falls. Nurses expressed, "help patient safety... If a patient is a fall risk, as soon as the patient gets out of the bed, the alarm rings... You're right there. So you can avoid big, big falls."

\section{Advantages for nurses}

Independent workspace reduces distraction Nurses commented that they had "less distraction" from other staff members at the pod station, “you're in your own space. You get to focus on your own things. Time management. You don't get all the chatter and everything else that you do at the nursing station."

\section{Disadvantages for patients}

Discussion at the pod station compromises patient privacy Compared to the centralized station where nurses exchanged patient information, nurses now gave shift report and discussed patient information with family members and other members of the healthcare team at the pod station outside of patient rooms. Nurses were concerned about patient privacy, "I feel like they might be able to hear you." However, nurses expressed that they were trying to speak in a low voice to avoid disclosing sensitive information to patients.

\section{Disadvantages for nurses}

Additional physical demands if receiving scattered assignments At the hybrid station where nurses work outside of patient rooms, they usually pick up an appropriate pod station that can easily cover all patient assignments. This put extra need for nurses to receive assignments that locate together. However, in some situations, for example, to make the appropriate/equal distribution of patients with serious conditions, they received scattered assignments, which made their work considerably more difficult, including additional walking and physical demands. Some nurses complained, "if you're in the midsection of the aisle, then you have to do both... that's a lot of walking... It was exhausting."

Enlarged physical environment and heavy assignments were issues discussed by most nurses. However, these issues may not be caused solely by the hybrid station. The enlarged environment and heavy assignments could be related to the hospital's organizational environment or the floor configuration. Participants explained that the large size of the unit affected how the charge nurse interacted with the staff nurses, "in the charge aspect... because the unit is so large, and there's so much to cover, and trying to find those different nurses to get updates and what not, it's not always feasible." Burnout from heavy assignments is a continuous issue in the healthcare institutions. Both nurses and nursing assistants mentioned the heavy workload with patients, "I think that the assignment load really needs to be lighter here for these nurses and for the aides. There needs to be more staffing. And I think that is the biggest problem solver that they could have on the floor."

\subsubsection{Transition to a hybrid station}

Transition to a hybrid station was defined as experience, facilitators, or barriers in the past two years of transition from the centralized station to the hybrid station. Most nurses expressed a difficult transition experience for the first six months, because the change from centralized to hybrid station involved behavioral changes among nurses to adapt to the new environment and new relationship with other team members.

\section{Reminiscence of the centralized station}

Thinking of the centralized station, especially the social interactions at the centralized station, was expressed by nurses. Although most participants did not oppose the pod station, they expressed nostalgia about the centralized station, " $a$ centralized nurse station, everyone was always sitting next to each other if they were at a computer, and they were always talking, or they were always asking each other questions, or talking about certain cases together"; "I enjoyed it...just being right there with everyone, and having an idea what was going on, and like you could name every patient and know what was going on.” 


\section{Lack of education about the pod station before transition}

Participants commented on the lack of education about pod station and attributed some of the function failure to this, "I can't say that I've learned very much as far as the pod nursing... I'm not sure what it is." Most participants expressed that it would be beneficial to receive training or education about pod nursing before coming to the floor.

\section{Inconsistency of pod utilization at different shifts}

During the transition period, nurses reported using the pod station inconsistently. They were accustomed to gathering with coworkers at the central station, but they were "kicked off the nurse station" and forced "in the little cubicles." Although the pod structure was enforced, nurses noted that different shifts enforced the policy differently. For instance, "I do 12 hour shifts. I end up being compliant on the 7-3 shift. 7-3, 3-5 pm, I'm still stuck in my pod. When I find out my boss is gone we kind of start to dwindle to where everybody is... back to the nurses' station."

\section{Recommendations for smooth transition}

Nurses provided recommendations to their peers for easier transition, "... People need to speak up if they think their assignment is too much... I think that people shouldn't be afraid to just say hey, I can't handle all of this, I'm going to need some help." Helping coworkers worked well at the hybrid station and promoted teamwork and communication. Mentorship was suggested by some nurses as an effective way to promote teamwork, "I think pairing someone who's more experienced on a floor with someone who's less experienced on the floor... that's ideal."

\section{Discussion}

This qualitative study was designed to examine nursing staff's experiences of communication and teamwork at the hybrid station and their perceptions of the advantages and disadvantages of the hybrid station. As discussed previously, communication patterns and behaviors can be affected by station design. ${ }^{[10]}$ Communication, and its effect on fostering teamwork, has been identified as the most crucial aspect in the delivery of quality care. ${ }^{[22]}$

Consistent with previous studies,,${ }^{[1,5,10]}$ we found that general communication and teamwork related to the hybrid design was compromised. Similarly to Tyson et al.,${ }^{[9]}$ nurses identified physical isolation, social isolation, and professional isolation as the biggest challenges to work at the hybrid station. However, different strategies were taken to promote communication and teamwork. As part of the station change, new technologies such as wireless phones have been implemented to enhance communication. Nurses use the wireless phones to locate and contact other team members which reduced time traveling to the central station and time spent looking for help. Guarascio-Howard reported that wireless technology can improve nurse communication and reduce time response to bed alarms. ${ }^{[23]}$

Contrary to previous studies that reported poor teamwork as a crucial concern by physicians and nurses, ${ }^{[24]}$ in this study, nurses were working toward creating a teamwork environment through reaching out for help and helping each other. Although teamwork was reported as a concern during the transition period, nurses developed strategies or were in the process of developing strategies to promote teamwork. New in this study, nurses mentioned that patient-centered interactions were fostered at the hybrid station due to proximity to patients. Although the centralized station provides spaces for nurses to communicate and socialize, participants reported most nurses spend time discussing their personal matters rather than patients. The design of the hybrid station fosters the nurses' communication of essential issues about patient care.

From the nurses' perception, the hybrid station has advantages for both patients and nurses. The intent of the hybrid layouts is to reduce the amount of walking for nurses and increase patient visibility with the ultimate goal to increase and lengthen time spent on patient care. ${ }^{[10]}$ Although some nurses reported exhaustion associated with scattered and heavy assignments, consistently, nurses reported reduced distraction and better time management due to independent workspaces. All nurses agreed that the hybrid design is more beneficial for patients through creating a quieter environment and increasing patient safety due to proximity to patients. The "pod team" structure and "morning huddles" with reports among "pod buddies" emerged from the transition and worked effectively in promoting teamwork and better patient care.

Duffy's (2005) Quality Care Model ${ }^{[25]}$ was implemented in this hospital to promote patient-centered care. Two important relationships were reinforced in the Quality Care Model: the independent patient-nurse relationship and the collaborative relationship. The independent patient-nurse relationship is most important and includes all interactions and interventions of which nurses are accountable for. The collaborative relationship includes the relationships that nurses share with other members of the healthcare team. The hybrid station design fits the Quality Care Model by improving the patientnurse relationship through increasing proximity to patients and fostering patient-centered interactions. On the other hand, advanced technology, "pod team" structure, and learning to work as a team enhanced the collaborative relationship 
among nurses. Through caring relationship with patients and collaborative relationship with other staff, nurses can provide an environment that patients can feel being cared for. ${ }^{[25]}$

Evidenced based designs are being adopted in health care facilities with the overarching goal of improving patient outcomes, providing a healing environment, and increasing nurses' job satisfaction. ${ }^{[13]}$ Participants reported the advantages of the hybrid station for both patients and nurses outweighed the disadvantages. As Donahue reported, ${ }^{[8]}$ the pod design has enhanced nurses' ability to provide safe and reliable care, evidenced by increased value-added care, such as patient-centered actions, and direct patient care time, and improved patient satisfaction. Effective interventions are needed to promote more social networking and interaction at the hybrid station. Possible practical strategies may include making oneself visible to others, using kudo/honor/thank you board to write personal messages, writing thank you notes to coworkers, organizing and participating in unit social activities such as pot lucks and Christmas parties, and celebrating staff birthdays. Frequent workplace communication and teamwork training is evidenced in improving staff interaction and performance, as well as providing safer patient care. ${ }^{[14,26,27]}$ The participatory action program may benefit intervention effectiveness in promoting teamwork through engaging employees in problem identification, decision-making, and implementation. ${ }^{[14]}$

The primary limitation of the study is the convenience sampling methods used to recruit study participants. Perspectives expressed by nursing staff in one community hospital may not be generalized to specific transitions in other hospitals.
However, the information collected may help to generate effective strategies that would improve nurses' communication and teamwork. Another limitation of the study is that we did not collect any observational data to objectively measure nurses' communication pattern and teamwork at the hybrid station, nor as well utilize any quantitative data to examine the effect of work station change on patient or nurse satisfaction and outcomes. However, the qualitative phenomenological design provided new information through allowing researchers to identify the essence of the phenomenon from the viewpoint of those nurses experiencing the work station transition, and helping researchers to identify complex phenomena through finding consistent patterns exhibited by participants. ${ }^{[28]}$

\section{Conclusions}

We used a qualitative phenomenological study to provide nurses' experiences of communication and teamwork at the hybrid station and their perceptions of the advantages and disadvantages of the hybrid station. Although isolation was reported as a big challenge, patient-centered interactions at the hybrid station and learning to work as a team were consistently identified by nursing staff. Overall the advantages of the hybrid station for both patients and nurses outweighed the disadvantages. Effective interventions are needed to reduce nurses' feelings of isolation and to support teamwork at the hybrid station.

\section{CONFlicts OF INTEREST Disclosure}

The authors declares that there is no conflict of interest.

\section{REFERENCES}

[1] Zborowsky T, Bunker-Hellmick L, Morelli A, et al. Centralized vs. decentralized nursing stations: effects on nurses' functional use of space and work environment. Health Environ Res Des J. 2010; 3(4): 19-44. http://dx.doi.org/10.1177/193758671000300404

[2] Chiang Y. Design dilemma: nurses' stations. 2010: 1-34. Available from: http://iwsp.human.cornell.edu/files/2013/ 09/Nurses-stations-qr3u4x.pdf

[3] Institute of Medicine, National Academies. Keeping patients safe: transforming the work environment of nurses. 1st ed. Washington: The National Academies Press; 2003. 484p. Available from: http: //www . nap.edu/openbook . php?record_id=10851\&page=R1

[4] Wakefield A. The changing "shape" of the nursing station. Contemp Nurse. 2002; 73: 148-157. http://dx.doi.org/10.5172/conu . 13.2-3.148

[5] Guarascio-Howard L, Malloch K. Centralized and decentralized nurse station design: an examination of caregiver communication, work activities, and technology. Health Environ Res Des J. 2007; 1(1): 44-57. http://dx.doi.org/10.1177/193758670700100114
[6] Harale KB. The role of design in communication, interaction, and teamwork [master's thesis]. [Ithaca (NY)]: Cornell University; 2010. 107p. Available from: http://iwsp.human.cornell.edu/fil es/2013/09/The-role-of-design-in-communication-int eraction-and-teamwork-uwygj1.pdf

[7] McCarthy M. Healthy design. Lancet. 2004 Jul; 364(9432): 405-406. Available from: http://www.thelancet.com/journals/lan cet/article/PIIS0140-6736\%2804\%2916787-1/fulltext http://dx.doi.org/10.1016/S0140-6736(04)16787-1

[8] Donahue L. A pod design for nursing assignments: eliminating unnecessary steps and increasing patient satisfaction by reconfiguring care assignments. Am J Nurs. 2009 Nov; 109(11 Suppl): 38-40. http: //dx.doi.org/10.1097/01.NAJ.0000362019.47504.9d

[9] Tyson G A, Lambert G, Beattie L. The impact of ward design on the behavior, occupational satisfaction and well-being of psychiatric nurses. Int J Ment Health Nurs. 2002 Jun; 11(2): 94-102. http://dx.doi.org/10.1046/j.1440-0979.2002.00232.x

[10] Hua Y, Becker F, Wurmser T, et al. Effects of nursing unit spatial layout on nursing team communication patterns, quality of care, 
and patient safety. Health Environ Res Des J. 2012; 6(1): 8-38. http://dx.doi.org/10.1177/193758671200600102

[11] Cai H, Zimring C. Out of sight, out of reach. Correlating spatial metrics of nurse station typology with nurses' communication and co-awareness in an intensive care unit. In proceedings of the Eighth International Space Syntax Symposium: 2012; Santiago, PUC. http://www.sss8.cl/media/upload/paginas/sec cion/Formato_-_8039_-_PDF.pdf

[12] Friese CR, Grunawalt JC, Bhullar S, et al. Pod nursing on a medi$\mathrm{cal} /$ surgical unit: implementation and outcomes evaluation. J Nurs Adm. 2014; 44(4): 207-211. http://dx.doi.org/10.1097/NNA .0000000000000051

[13] Ulrich R, Zimring C, Barch X, et al. A review of the research literature on evidence-based healthcare design (part I). Health Environ Res Des J. 2008; 3(1): 1-99. Available from: https: //smartech.gatech.edu/bitstream/handle/1853/25676/ zimring_HERD_2008_researchlitreview . pdf?sequence=1

[14] Clark PR. Teamwork: Building healthier workplaces and providing safer patient care. Crit Care Nurs Q. 2009 Jul-Sep; 32(3): 221-231. http://dx.doi.org/10.1097/CNQ.0b013e3181ab923f

[15] Kalisch BJ, Lee KH. The impact of teamwork on missed nursing care. Nurs Outlook. 2010 Sep; 58: 233-241. http://dx.doi.org $/ 10.1016 / j$. outlook.2010.06.004

[16] Kalisch BJ, Lee K H, Rochman M. Nursing staff teamwork and job satisfaction. J Nurs Manag. 2010 Nov; 18(8): 938-947. http: //dx.doi.org/10.1111/j.1365-2834.2010.01153.x

[17] Moustakas C. Phenomenological research methods. 1st ed. Thousand Oaks, CA: Sage; 1994. 208p.

[18] Mergler D. Combining quantitative and qualitative approaches in occupational health for a better understanding of the impact of workrelated disorders. Scand J Work. 1999 Sep; 25(Suppl. 4): 54-60. Available from: http://www . jstor.org/stable/40967007

[19] Merton RK, Lowenthal MF, Kendall PL. The focused interview: a manual of problems and procedures. 2nd ed. New York (NY): Free Press; 1990. 413p.
[20] Strauss A, Corbin J. Basics of qualitative research: Grounded theory procedures and techniques. 2nd ed. Thousand Oaks (CA): Sage Publications Inc; 1990. 270p.

[21] Maxwell JA. Understanding and validity in qualitative research. In: Huberman AM, Miles MB, eds. The qualitative researcher's companion. Thousands Oaks, CA: Sage Publications Inc; 1992: 37-64. http: //dx.doi.org/10.17763/haer.62.3.8323320856251826

[22] The Joint Commission. Advancing effective communication, cultural competence, and patient-and family-centered care: a roadmap for hospitals [Internet]. Oakbrook Terrace (IL): The Joint Commission; 2010. 93 p. Available from: http: //www . joint commission. org/asse ts/1/6/ARoadmapforHospitalsfinalversion727.pdf

[23] Guarascio-Howard L. Examination of wireless technology to improve nurse communication, response time to bed alarms, and patient safety. Health Environ Res Des J. 2011; 4(2): 109-120. http://dx.doi.org/10.1177/193758671100400209

[24] Maxfield D, Grenny J, Patterson K, et al. Silence kills: the seven crucial conversations for health care. Vital Smarts. 2005. E45. Available from: http://www . aacn.org/WD/Practice/Docs/Pu blicPolicy/SilenceKills.pdf

[25] Duffy JR. Implementing the Quality-Caring Model in acute care. J Nurs Adm. 2005; 35(1): 4-6. http://dx.doi.org/10.1097/000 05110-200501000-00002

[26] Gysels M, Richardson A, Higginson IJ. Communication training for health professionals who are for patients with cancer: a systematic review of effectiveness. Support Care Cancer. 2004 Oct; 12: 692-700. http://dx.doi.org/10.1007/s00520-004-0732-0

[27] Morey JC, Simon R, Jay GD, et al. Error reduction and performance improvement in the Emergency Department through formal teamwork training: evaluation results of the MedTeams project. Health Serv Res. 2002 Dec; 37(6): 1553-1581. http://dx. doi .org/10. 1111/1475-6773.01104

[28] Morey NC, Morey RV. Organizational culture: the management approach. Natl Assoc Pract Anthropol Bull. 2008; 14(1): 17-26. http://dx.doi.org/10.1525/napa.1994.14.1.17 